\title{
Composição químico-bromatológica da silagem de capim-elefante com níveis de casca de café 1
}

\author{
Dawson José Guimarães Faria², Rasmo Garcia ${ }^{3}$, Odilon Gomes Pereira ${ }^{3}$, Dilermando \\ Miranda da Fonseca ${ }^{3}$, Renius Mello ${ }^{2}$, João Paulo Sampaio Rigueira ${ }^{4}$
}

\footnotetext{
1 Parte da dissertação de Mestrado do primeiro autor.

2 Doutorando em Zootecnia - UFV.

3 Departamento de Zootecnia - UFV. Bolsista do CNPq.

${ }^{4}$ Mestrando em Zootecnia - UFV.
}

RESUMO - Objetivou-se avaliar os efeitos do processamento (inteira ou moída) e da inclusão de diferentes níveis de casca de café $(0,6,12,18$ e $24 \%$ da matéria natural) sobre a composição químico-bromatológica, as características fermentativas e a digestibilidade in vitro da MS (DIVMS) de silagens de capim-elefante. A s variáveis foram analisadas em esquema fatorial 2 x 5, em delineamento experimental inteiramente casualizado, com três repetições. O processamento e a inclusão de casca de café aumentaram os teores de MS das silagens, observando-se que a inclusão de casca inteira, em comparação à casca moída, proporcionou maior teor de MS. O processamento e os níveis de casca de café não influenciaram os teores de PB das silagens. Os níveis de casca de café tiveram efeito linear sobre os teores de FDN e FDA, ocasionando decréscimo de FDN e aumento de FDA. O processamento e os níveis de inclusão influenciaram os teores de lignina. Os níveis de casca de café, não o processamento, tiveram efeito quadrático sobre os teores de nitrogênio insolúvel em detergente neutro e ácido. Houve efeito da interação processamento $\times$ nível de inclusão sobre o pH, que sofreu efeito quadrático dos níveis de inclusão nos dois processamentos. Verificou-se efeito linear dos níveis de casca de café sobre os valores de nitrogênio amoniacal, que diminuíram conforme aumentaram os níveis de inclusão, sendo menores para a casca moída. A DIVMS sofreu efeito quadrático dos níveis de inclusão, sendo inferior na silagem com casca inteira em comparação à casca moída. A casca de café foi eficiente como aditivo absorvente nas silagens e, apesar de não ter melhorado as características bromatológicas das silagens, pode ser utilizada inteira ou moída, em proporções de até $12 \%$, para melhorar as características fermentativas da silagem.

Palavras-chave: aditivo absorvente, ensilagem, processamento, valor nutritivo

\section{Chemical composition of elephant grass silages as affected by coffee hulls addition levels}

\begin{abstract}
The experiment aimed to evaluate the effects of processing (whole or ground) and the inclusion level of coffee hulls, $(0 ; 6 ; 12 ; 18$ and $24 \%$; fresh matter basis) on the chemical-bromatological composition, fermentation characteristic and in vitro DM digestibility (IVDMD) of the elephantgrass silages. The variables were analyzed as a $2 \times 5$ factorial arrangement (processing and level of inclusion), distributed in a complete randomized experimental design with three replications. Processing and level of inclusion increased DM concentration and did not influence the crude protein concentration of silages. Linear effect of the inclusions level on NDF and ADF was observed, with decrease of NDF and increase of ADF. Processing and level of inclusions influenced the lignin concentration. Quadratic effect of inclusions level was observed for neutral and acid detergent insoluble nitrogen concentration. There was an interaction between processing and level of inclusions on $\mathrm{pH}$. A quadratic effect of the inclusion level on the two processing forms was observed. Linear reduction of the ammoniacal nitrogen was observed with the level of inclusion, with higher values for ground hulls. For IVDMD, a quadratic effect was observed as a function of the inclusion level, with IVDMD of whole hulls being lower compared to the ground hulls. The coffee hull was efficient as an additive to reduce humidity of the silages. Coffee hull addition did not improve silage bromatological characteristics but it did improve fermentative characteristics. Thus, inclusion of the coffe hull could be adapted until the level of $12 \%$, whole or ground.
\end{abstract}

Key Words: absorbent additive, ensilage, nutritive value, processing 


\section{Introdução}

A menor produção de forragem durante o outono e o inverno tem sido apontada como um dos fatores que contribuem para a baixa produtividade dos rebanhos brasileiros mantidos em pastagem. Neste contexto, é indiscutível a importância da silagem como volumoso suplementar na alimentação de ruminantes em períodos de escassez de forragem.

As silagens de gramíneas, inclusive a de capim-elefante, constituem alternativa às culturas tradicionais como milho e sorgo, visto que as gramíneas têm elevada produção de MS e são culturas perenes, de menor custo por tonelada de MS em relação às plantas tradicionais e maior flexibilidade na colheita. O capim-elefante apresenta, no entanto, algumas características intrínsecas, observadas no estádio fisiológico ideal para corte, que interferem na fermentação, como baixos teores de carboidratos solúveis e de MS, que dificultam a obtenção de silagens de boa qualidade (Lavezzo, 1985).

O baixo teor de MS favorece a atuação de microrganismos do gêneroClostridium, responsáveis pelas maiores perdas por fermentação, tanto em relação ao teor de MS como de energia, que, em conjunto, podem assinalar perdas de 50 e $18 \%$ para MS e energia, respectivamente (McDonald et al., 1991, citados por Balsalobre et al., 2001). Portanto, para obtenção de silagens de capim-elefante de melhor qualidade, as restrições quanto à umidade excessiva devem ser corrigidas.

O emurchecimento da forragem antes da ensilagem e o uso de aditivos absorventes são as técnicas mais recomendadas para elevação do teor de MS da forrageira a ser ensilada. Apesar de ser uma prática recomendada, o emurchecimento tem sido bastante questionado pelo fato de demandar práticas que encarecem todo o processo de ensilagem e, muitas vezes, ser limitado pelas condições climáticas.

No Brasil, há grande produção de resíduos agro-industriais, destacando-se a de casca de café (CA), subproduto utilizado como aditivo absorvente na ensilagem de gramíneas ou como parte da dieta de ruminantes. A utilização da CA na alimentação de ruminantes pode promover redução do consumo voluntário dos bovinos, com reflexo significativo no desempenho animal, principalmente quando é o principal alimento da dieta, pois alguns compostos presentes na casca podem ter efeito negativo no consumo animal, como cafeína, taninos e polifenóis, além de altos teores de lignina (Cabezas et al., 1978).

Vilela et al. (2001) concluíram que é possível substituir até $42 \%$ do volumoso (cana-de-açúcar e capim-elefante) da dieta pela CA melosa. Quadros et al. (2002) verificaram que a inclusão de até $10 \%$ de CA na silagem de capim-elefante não reduziu a degradabilidade da MS. Bernardino et al. (2005) verificaram que a inclusão de até $10 \%$ de CA na ensilagem de capim-elefante não compromete o consumo e a digestibilidade dos nutrientes.

Segundo Jones \& Jones (1996), a capacidade de retenção de umidade dos aditivos absorventes pode variar com o tipo de material utilizado, observando-se que materiais com maior lignificação têm maior capacidade de retenção de água. Entretanto, de acordo com esses autores, apesar de altamente absorventes, esses aditivos reduzem o valor nutritivo da silagem. Outra característica importante que afeta a capacidade de retenção de água pelo aditivo é seu grau de moagem. Dexter (1961), citado por Jones \& Jones (1996), comparou a capacidade de retenção de efluente de alguns materiais (grão moído de milho, sabugo de milho, aveia moída, trigo moído, polpa de beterraba e palha de aveia) e concluiu que os materiais finamente moídos foram mais eficientes na retenção de efluente. Todavia, a moagem aumenta custos, sendo necessário analisar a relação custo:benefício para a adoção desta prática.

Este trabalho foi conduzido com o objetivo de verificar o efeito da moagem da CA e de sua inclusão, em diferentes níveis, sobre a composição bromatológica e a digestibilidade in vitro da MS (DIVMS) de silagens de capim-elefante.

\section{Material e Métodos}

O experimento foi conduzido no Departamento de Zootecnia da Universidade Federal de Viçosa (UFV), Viçosa-MG, no período de 27/01/2004 a 27/04/2004. As análises laboratoriais foram realizadas nos Laboratórios de Forragicultura e Nutrição Animal do Departamento de Zootecnia da Universidade Federal de Viçosa.

A espécie forrageira utilizada foi o capim-elefante (Pennisetum purpureum Schum), cultivar Cameroon, oriundo de uma capineira estabelecida no Departamento de Zootecnia da UFV, em área de baixada adubada anualmente com esterco de curral.

A CA utilizada foi adquirida em Viçosa; parte foi triturada em moinho tipo martelo com peneira de $3 \mathrm{~mm}$. O capimelefante foi cortado manualmente no dia 27 de janeiro de 2004, sendo picado em partículas de 2 a $5 \mathrm{~cm}$ de comprimento, utilizando-se máquina forrageira acoplada a um trator, e ensilado no mesmo dia. No momento do corte, o capimelefante estava com aproximadamente 70 dias de idade (rebrota) e 1,80 m de altura.

A CA inteira ou moída foi adicionada ao capim recémpicado nos níveis de $0,6,12,18$ e $24 \%$, com base na matéria natural $(0,60,120,180$ ou $240 \mathrm{~kg}$ de CA por tonelada de capim verde), e misturada até homogeneização, procedendo-se 
em seguida à ensilagem em silos laboratoriais de PVC $(0,25$ $\mathrm{m}$ de diâmetro e $0,75 \mathrm{~m}$ de altura). A parte inferior do silo, onde poderia haver frestas que prejudicassem a vedação, foi vedada com silicone. Em cada silo, foram colocados $10 \mathrm{~kg}$ da mistura de capim e CA. A massa ensilada foi compactada com auxílio de soquetes até a altura de $0,37 \mathrm{~m}$, obtendo-se densidade de $550 \mathrm{~kg} / \mathrm{m}^{3}$. Após o enchimento, os silos foram vedados com tampa de madeira revestida com plástico e cobertos com sacos plásticos para evitar a entrada de água e oxigênio. Durante a ensilagem, foram coletadas amostras do capim-elefante e da CA, que foram armazenadas em freezer para posteriores análises.

A composição químico-bromatológica do capim-elefante e da CA utilizados na produção das silagens é apresentada na Tabela 1.

Após 90 dias de ensilagem, os silos foram abertos e todo o seu conteúdo foi retirado e homogeneizado sobre uma lona, retirando-se três amostras de cada unidade experimental. A primeira amostra foi colocada em sacos de papel, sendo pesada e mantida em estufa de ventilação forçada a $65^{\circ} \mathrm{C}$ por 72 horas. Posteriormente, as demais amostras foram retiradas da estufa e deixadas em temperatura ambiente por uma hora, sendo pesadas novamente para determinação da matéria pré-seca. Em seguida, foram trituradas em moinho Wiley com peneira de $1 \mathrm{~mm}$ e armazenadas em potes de plásticos com tampa para posteriores análises. A segunda amostra foi utilizada para análise do $\mathrm{pH}$ e do

Tabela 1 - Composição químico-bromatológica do capim-elefante e da casca de café utilizados na produção das silagens

Table 1 - Chemical composition of elephantgrass and coffee hulls used for silage production

\begin{tabular}{|c|c|c|}
\hline $\begin{array}{l}\text { Item } \\
\text { Item }\end{array}$ & $\begin{array}{c}\text { Capim-elefante } \\
\text { Elephantgrass }\end{array}$ & $\begin{array}{c}\text { Casca de café } \\
\text { Coffee hulls }\end{array}$ \\
\hline $\operatorname{MS}(D M)$ & 12,72 & 81,20 \\
\hline $\mathrm{PB}(C P)^{1}$ & 11,79 & 8,16 \\
\hline $\mathrm{FDN}(N D F)^{1}$ & 66,67 & 62,20 \\
\hline FDA $(A D F)^{1}$ & 47,17 & 50,35 \\
\hline $\operatorname{NIDN}(N D I N)^{2}$ & 24,69 & 37,12 \\
\hline NIDA $(A D I N)^{2}$ & 5,34 & 23,62 \\
\hline Lignina $(\text { Lignin })^{1}$ & 11,32 & 16,86 \\
\hline Celulose (Cellulose) $)^{1}$ & 35,85 & 35,91 \\
\hline Hemicelulose (Hemicellulose) ${ }^{1}$ & 19,50 & 11,85 \\
\hline $\mathrm{EE}^{1}$ & 1,24 & 0,97 \\
\hline Cinzas $(A s h)^{1}$ & 12,05 & 5,78 \\
\hline $\mathrm{Ca}^{1}$ & 0,38 & 0,29 \\
\hline $\mathrm{P}^{1}$ & 0,28 & 0,13 \\
\hline $\mathrm{Na}^{1}$ & 0,02 & 0,01 \\
\hline $\mathrm{K}^{1}$ & 3,92 & 2,17 \\
\hline $\mathrm{Mg}^{1}$ & 0,21 & 0,07 \\
\hline DIVMS $(I V D M D)^{1}$ & 68,23 & 50,79 \\
\hline
\end{tabular}

$1 \% \mathrm{MS} ; 2 \%$ do nitrogênio total.

${ }^{1} \mathrm{DM} \% ;{ }^{2}$ total nitrogen \%. nitrogênio amoniacal $\left(\mathrm{N}-\mathrm{NH}_{3}\right)$ das silagens e a terceira foi colocada em sacos plásticos previamente identificados e armazenada em freezer para uso em caso de perda de amostra.

Os teores de MS, PB, FDN, FDA, NIDN, NIDA, lignina (permanganato), celulose, hemicelulose, EE, cinzas e minerais ( $\mathrm{Ca}, \mathrm{Mg}, \mathrm{Na}, \mathrm{Ke} \mathrm{Mn}$ ), a digestibilidadein vitro da $\mathrm{MS}$ (DIVMS) e o pH da silagem foram determinados segundo metodologia descrita por Silva \& Queiroz (2002). O nitrogênio amoniacal foi determinado conforme descrito por Bolsen et al. (1992).

A composição químico-bromatológica da silagem foi estudada utilizando-se um esquema fatorial 2 x 5, composto de dois processamentos - PR (com ou sem moagem) e cinco níveis de CA $(0,6,12,18$ e $24 \%$ da matéria natural), dispostos em um delineamento inteiramente casualizado, com três repetições.

Os dados obtidos foram estudados em cada PR e nível de inclusão de CA e submetidos às análises de variância e regressão, utilizando-se o programa SAEG - Sistema de Análise Estatística e Genética (UFV, 1997). Para o efeito do PR, foi utilizada a variável Dummy, atribuindo-se na equação valor 0 para casca inteira (sem PR) e valor 1 para casca moída (com PR).

\section{Resultados e Discussão}

Os teores de MS das silagens com níveis de inclusão de CA inteira ou moída, sua respectiva equação de regressão e seu coeficiente de determinação são apresentados na Figura 1. Verificou-se efeito linear $(\mathrm{P}<0,05)$ da inclusão de CA sobre o teor de MS da silagem. Não houve efeito direto (P>0,05) do PR no teor de MS da silagem - apenas da interação nível de inclusão $\times \mathrm{PR}(\mathrm{P}<0,05)$. A elevação do teor de MS com a inclusão de CA deve-se ao alto teor de MS da casca $(81,2 \%)$ e à sua boa capacidade de retenção de umidade; a silagem com $0 \%$ de casca apresentou teor de MS similar ao do capim-elefante no momento da ensilagem. Bernardino et al. (2005) também verificaram efeito da inclusão de CA sobre o teor de MS da silagem, com acréscimo linear de 0,69\% no teor de MS para cada unidade percentual de casca adicionada, efeito próximo ao verificado neste experimento $(0,59 \%$ por unidade percentual de casca adicionada). Souza et al. (2003), também estudando a inclusão de CA na silagem de capim-elefante, verificaram acréscimos, porém menores $(0,54 \%)$, no teor de MS por unidade percentual de CA adicionada. Com a inclusão de $24 \%$ de CA, estimaram-se valores de 24,38 e $26,48 \%$ de MS para casca inteira e moída, respectivamente, bem próximos aos de 20 e $25 \%$ propostos, respectivamente, por McDonald (1981) e 

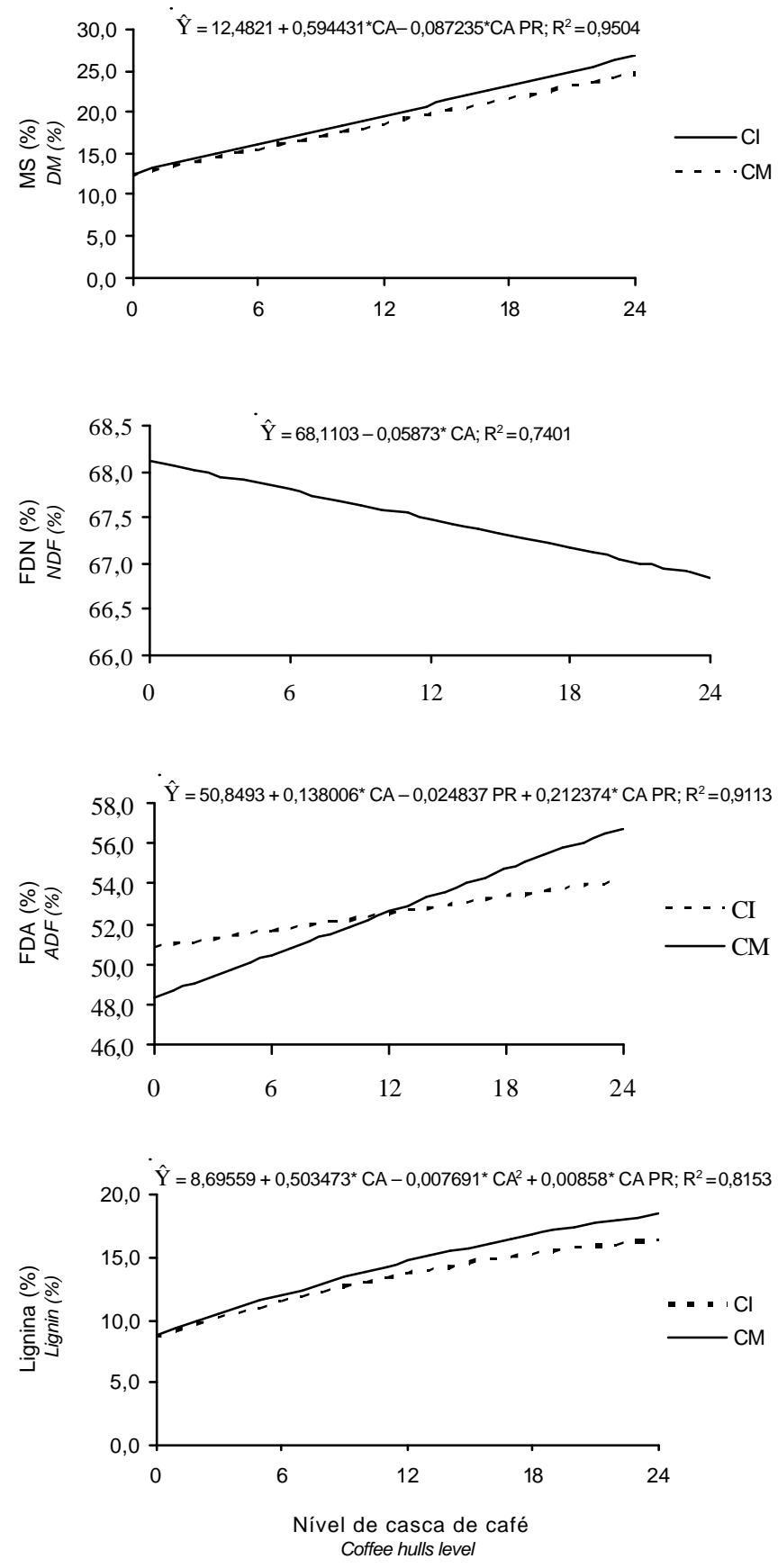

Figura 1 - Teores de MS, FDN, FDA e lignina da silagem de capimelefante produzida com diferentes níveis de casca de café inteira $(\mathrm{Cl})$ ou moída (CM) ( ${ }^{\star}$ Significativo a $5 \%$ de probabilidade pelo teste $\mathrm{t}$ ).

Figure 1 - Concentrations of DM, NDF, ADF and lignin of elephantgrass silage with different inclusion levels of coffee hulls, whole (Cl) or ground (CM) (Significant at $5 \%$ probability by $t$ test).

Andrade (1995) comomínimo para que não ocorram perdas na ensilagem do capim-elefante.

Igarasi (2002) sugeriu que, em gramíneas tropicais, para mesmo teor de umidade da massa ensilada, haveria menor atividade da água na forragem de plantas de clima temperado, como resultado de possível maior carga iônica no conteúdo celular, o que permitiria maior sucesso no controle de microrganismos indesejáveis, como Clostridium, mesmo sob teores mais reduzidos de MS na massa de forragem ensilada ( $<30 \%$ de MS).

Verificou-se efeito quadrático da inclusão de $\mathrm{CA}(\mathrm{P}<0,05)$ sobre os valores de $\mathrm{pH}$ das silagens (Figura 2). Detectou-se também efeito do PR, estimando-se pH mínimo de 3,87 para a casca inteira $(18,59 \%)$ e de 3,95 para casca moída $(9,87 \%)$. $\mathrm{Na}$ ausência de $\mathrm{CA}$, o maior valor de $\mathrm{pH}$ da silagem com casca inteira pode ter sido ocasionado pelo fato de uma das repetições para este processamento estar deteriorada e com $\mathrm{pH}$ muito superior ao das outras repetições.

Souza et al. (2003) também observaram efeito quadrático dos níveis de inclusão de CA $(0 ; 8,7 ; 17,4 ; 26,1$ e 34,8\%, com base na matéria natural) sobre o $\mathrm{pH}$ de silagens de capimelefante e estimaram valor mínimo de 3,78 para o nível de $26,87 \%$ de casca. Por outro lado, Bernardino et al. (2003) observaram que o $\mathrm{pH}$ decresceu linearmente com a adição de CA e relataram que, com o aumento do teor de MS, foi criado um ambiente favorável ao desenvolvimento de bactérias láticas (desfavorável para as do gênero Clostridium). Além disso, a CA forneceu carboidratos solúveis, o que contribui para rápida diminuição do $\mathrm{pH} \mathrm{e}$ redução do pH final das silagens. Evangelista et al. (1996), no entanto, não observaram diferenças entre os níveis (5 e 10\%) e as formas físicas (solta, peletizada e peletizadatriturada) de polpa cítrica nos teores de $\mathrm{pH}$ das silagens de capim-elefante. Pinto et al. (2004), também trabalhando com inclusão de $0,5,10$ e $15 \%$ de polpa cítrica peletizada para ensilagem de capim-aruana em diferentes idades de crescimento (40, 80 e 120 dias), nãoencontraram efeito da inclusão da polpa no $\mathrm{pH}$ das silagens. Esses autores observaram que os valores médios permaneceram próximos a 4.

O pH das silagens com $24 \%$ de casca moída foi de 4,29 e, mesmo com esta elevação para os maiores níveis de casca moída, o $\mathrm{pH}$ foi próximo a 4,2, valor adequado para a conservação da forragem. As silagens apresentaram ainda bom padrão de conservação e bom aspecto e odor. Segundo Van Soest (1994), em silagens com alto teor de MS, o pH é menos importante, podendo ser obtidas silagens de boa qualidade mesmo com $\mathrm{pH}$ mais elevados.

Conforme descrito na Tabela 2, os valores de PB das silagens não foram influenciados $(\mathrm{P}>0,05)$ pelos níveis de CA ou pelo PR, sendo obtido valor médio de $10,25 \%$ desse nutriente, provavelmente porque as maiores perdas de nitrogênio total (NT) no efluente e o maior teor de nitrogênio amoniacal $\left(\mathrm{N}-\mathrm{NH}_{3}\right)$ na silagem sem casca (Figura 3) foram compensados pelo maior teor de PB do capim $(11,79 \%)$ em comparação à casca $(8,16 \%)$.

Souza et al. (2001) observaram que o valor de PB da silagem se manteve em $11 \%$ com a adição de CA, próximo ao 


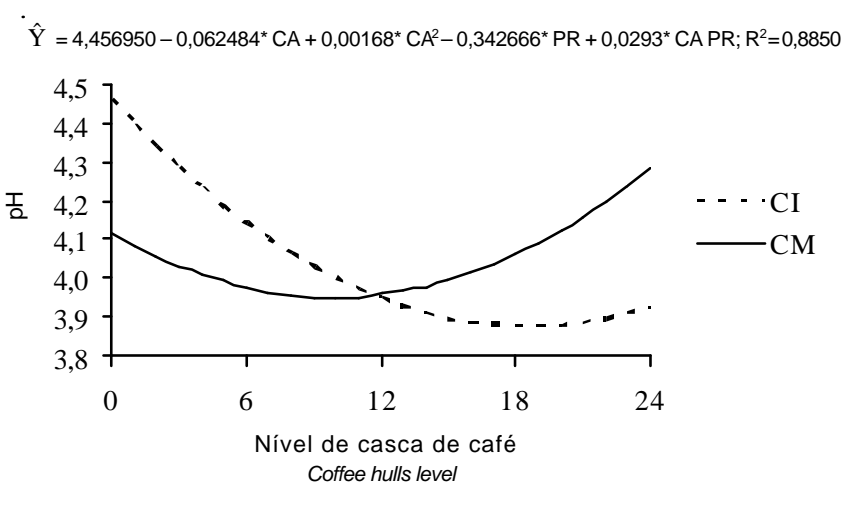

Figura 2 - pH da silagem de capim-elefante produzida com diferentes níveis de casca de café inteira $(\mathrm{Cl})$ ou moída (CM) ( ${ }^{*}$ Significativo a $5 \%$ de probabilidade pelo teste $\mathrm{t}$ ).

Figure 2 - $\quad \mathrm{pH}$ of elephantgrass silage as a function of different levels of coffee hulls, whole (Cl) or ground (CM) ( ${ }^{*}$ Significant at $5 \%$ probability by $t$ test).

verificado para o capim-elefante no momento da ensilagem. Esses autores relataram ainda que a silagem sem CA teve o teor de $\mathrm{PB}$ reduzido, fato atribuído à perda de compostos nitrogenados solúveis no efluente. Outros autores (Evangelista et al., 1999; Corrêa \& Cordeiro, 2000; Ávila et al., 2003) também não observaram aumento no teor protéico em silagens produzidas com níveis crescentes de polpa cítrica. Herling (1998) observou o mesmo para silagens com fubá de milho. Evangelista et al. (1996) verificaram também diferença no teor de PB com a inclusão de polpa cítrica em diferentes formas físicas (solta, peletizada e peletizadatriturada) na silagem de capim-napier.

Os valores de nitrogênio amoniacal $\left(\mathrm{N}-\mathrm{NH}_{3}\right)$ sofreram efeito linear decrescente dos níveis de CA e do $\mathrm{PR}(\mathrm{P}<0,05)$ (Figura 3).

Os menores valores de $\mathrm{N}-\mathrm{NH}_{3}$ obtidos com a inclusão de CA podem ser atribuídos à elevação da MS da silagem, que reduz a atividade dos microrganismos do gênero Clostridium, responsáveis pela proteólise de aminoácidos (McDonald, 1981). Bernardino et al. (2005) verificaram redução

Tabela 2 - Teores médios de PB (\% MS) da silagem de capimelefante com diferentes níveis de casca de café inteira ou moída

Table 2 - Mean CP concentration (CP, \% DM) of elephantgrass silage with different inclusion levels of coffee hulls, whole or ground

\begin{tabular}{|c|c|c|c|c|c|c|}
\hline \multirow[t]{2}{*}{$\begin{array}{l}\text { Casca de café } \\
\text { Coffee hulls }\end{array}$} & \multicolumn{5}{|c|}{$\begin{array}{c}\text { Casca de café }(\%) \\
\text { Coffee hulls }(\%)\end{array}$} & \multirow[t]{2}{*}{$\begin{array}{c}\text { Média } \\
\text { Mean }\end{array}$} \\
\hline & 0 & 6 & 12 & 18 & 24 & \\
\hline Inteira & 9,83 & 10,08 & 10,40 & 10,17 & 9,78 & 10,05 \\
\hline $\begin{array}{l}\text { Whole } \\
\text { Moída }\end{array}$ & 10,45 & 10,30 & 10,60 & 10,58 & 10,31 & 10,45 \\
\hline
\end{tabular}

$\hat{Y}=15,9431-0,428799^{*} \mathrm{CA}-2,32742^{*} \mathrm{PR} ; \mathrm{R}^{2}=0,8016$

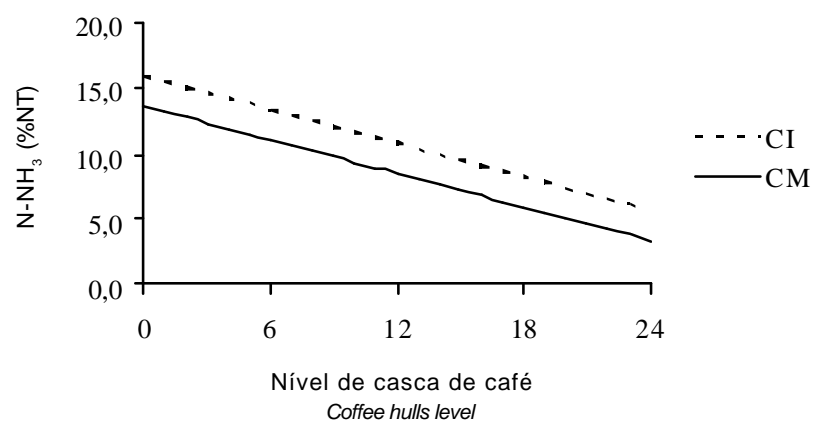

Figura 3 - Teores de $\mathrm{N}-\mathrm{NH}_{3}$ da silagem de capim-elefante produzida com diferentes níveis de casca de café inteira (Cl) ou moída (CM) (* Significativo a $5 \%$ de probabilidade pelo teste $\mathrm{t}$ ).

Figure 3 - $\quad \mathrm{NH}_{3}-\mathrm{N}$ concentration of elephantgrass silage with different inclusion levels of coffee hulls, whole (Cl) or ground (CM) ${ }^{*}$ Significantat $5 \%$ probability by $t$ test).

nos teores de $\mathrm{N}-\mathrm{NH}_{3}$ com a adição de $\mathrm{CA}$ e registraram valores bastante baixos (1,9\% do NT). Os valores de $\mathrm{N}-\mathrm{NH}_{3}$ encontrados por esses autores para as silagens sem CA ( $28,7 \%$ do NT) foram bem mais elevados que os observados neste experimento $(17,75 \%$ do NT). NaFigura 3 , observa-se ainda o efeito do PR; a casca moída apresentou menores teores de $\mathrm{N}-\mathrm{NH}_{3}$ em comparação à casca inteira. Evangelista et al. (1996), no entanto, verificaram que os teores de $\mathrm{N}-\mathrm{NH}_{3}$ não diferiram significativamente entre os níveis e as formas físicas da polpa cítrica.

$\mathrm{Na}$ silagem, baixo teor de nitrogênio amoniacal $\left(\mathrm{N}-\mathrm{NH}_{3}\right)$, inferior a $10 \%$ do nitrogênio total (NT), indica que o processo de fermentação não resultou em quebra excessiva da proteína em amônia (Van Soest, 1994). Ao contrário, um teor de $\mathrm{N}-\mathrm{NH}_{3}$ superior a $15 \%$ do NT significa que a quebra de proteínas foi considerável. Essas silagens podem ser menos aceitas pelos animais, resultando em baixo consumo. $\mathrm{O}$ teor de $\mathrm{N}-\mathrm{NH}_{3}$ também indica a atividade das bactérias do gênero Clostridium, pois é produzido somente em pequenas quantidades por outros microrganismos e enzimas das plantas (McDonald, 1981).

Para os valores de nitrogênio insolúvel em detergente neutro (NIDN), os dados tiveram ajuste quadrático (Figura 4). A CA, independentemente do PR, influenciou os teores de NIDN $(\mathrm{P}<0,05)$, sendo observado efeito quadrático, atribuído ao maior conteúdo de NIDN da CA (37,12\% do NT) em comparação ao do capim $(24,69 \%$ do NT) no momento da ensilagem. Foi estimado valor máximo de $31,70 \%$ de NIDN com a inclusão de $22,47 \%$ de CA.

Resultados semelhantes aos de NIDN também foram encontrados para NIDA (nitrogênio insolúvel em detergente ácido) (Figura 4). Estimou-se teor máximo de NIDA 
de $21,49 \%$ quando adicionada casca de café na proporção de 20,67\%. Bernardino et al. (2005) encontraram efeito linear positivo da inclusão de casca de café nos valores de NIDA da silagem de capim-elefante e atribuíram o fato ao maior valor desse componente na casca de café (39,8\%) em relação ao capim-elefante (12,9\%). Souza et al. (2003), de forma semelhante, observaram efeito linear dos níveis de CA sobre os teores de NIDA das silagens de capimelefante. Esses autores, citando Van Soest \& Mason (1991) e Licitra et al. (1996), relataram que o aumento no teor de NIDA não é desejável, pois o nitrogênio retido na FDA não é aproveitado pelas bactérias ruminais. Durante a secagem e o beneficiamento do café, o grão sofre aquecimento, o que pode justificar o elevado teor de NIDA da casca deste produto.

Como pode ser observado na Figura 1, o teor de FDN foi influenciado apenas pelos níveis de $\mathrm{CA}(\mathrm{P}<0,05)$ na silagem, sendo estimado valor de $68,11 \%$ de FDN para a silagem sem CA, com redução linear de $0,058 \%$ para cada unidade de casca adicionada. Não houve efeito do PR ou da interação sobre os teores de FDN $(\mathrm{P}>0,05)$. O maior valor de

$\hat{Y}=14,9782+1,48872^{\star} C A-0,033124^{*} C A^{2} ; R^{2}=0,8702$

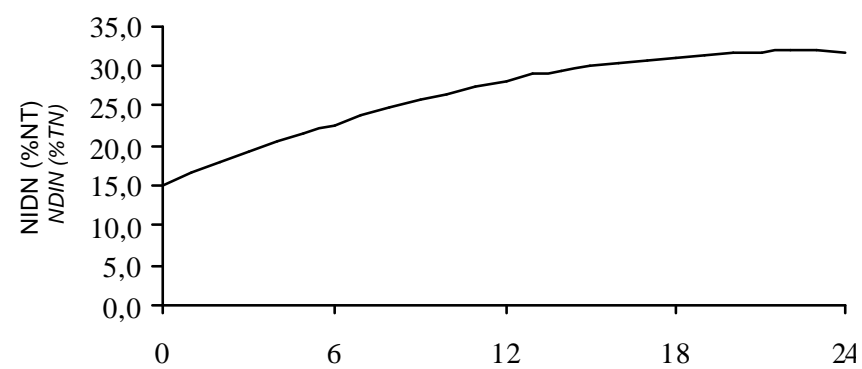

$\hat{\mathrm{Y}}=6,68639+1,43252 * \mathrm{CA}-0,034652 * \mathrm{CA}^{2} ; \mathrm{R}^{2}=0,8153$

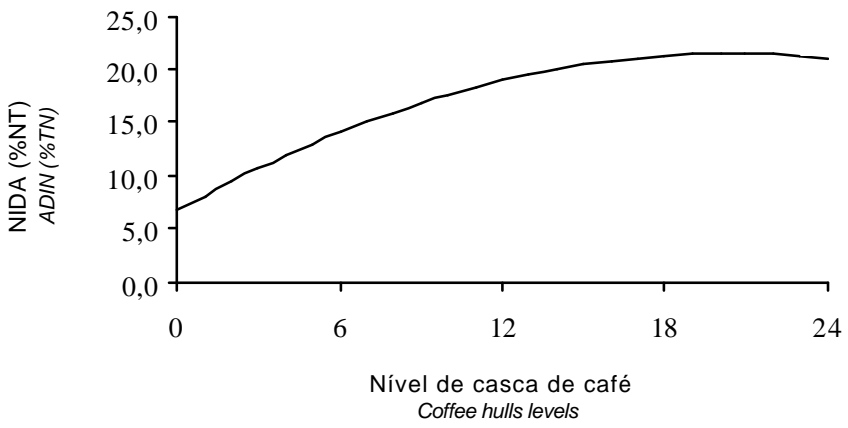

Figura 4 - Teores de NIDN e NIDA da silagem de capim-elefante produzida com diferentes níveis de casca de café ( ${ }^{*}$ Significativo a $5 \%$ de probabilidade pelo teste $\mathrm{t}$ ).

Figure 4 - NDIN and ADIN concentration of elephantgrass silage with different inclusion levels of coffee hulls (Significant at $5 \%$ probability by $t$ test).
FDN da silagem sem CA $(68,11 \%)$ em comparação ao do capim $(66,67 \%)$ pode ser explicado pela perda de componentes solúveis da MS pelo efluente, o que aumenta os teores dos componentes da parede celular (McDonald, 1981). De modo semelhante, Bernardino et al. (2005) e Souza et al. (2003) encontraram efeito linear da inclusão de CA sobre os teores de FDN das silagens de capim-elefante. Ferrari Jr. \& Lavezzo (2001) verificaram redução linear nos valores de FDN da silagem de capim-elefante acrescida de farelo de mandioca (0,2, 4, 8 e 12\%). Crestana et al. (2001) observaram a mesma tendência ao incluírem 5 ou $10 \%$ de polpa cítrica na silagem de capim-tanzânia e verificaram declínio do teor de FDN-de 68,1\% (0\%) para 63,9\% (5\%) e 60,8\% (10\%)-como efeito do baixo de teor de FDN da polpa cítrica.

Como demonstrado na Figura 1, os teores de FDA das silagens tiveram ajuste linear crescente nos níveis de inclusão de CA, sendo observado ainda efeito do PR e da interação $\mathrm{CA} \times \mathrm{PR}(\mathrm{P}<0,05)$. Este comportamento pode ser explicado pelo aumento dos teores de lignina com a inclusão de CA, visto que a FDA é composta principalmente pelas frações lignina e celulose (Van Soest, 1994). Além disso, o maior teor de FDA da casca $(50,35 \%)$ em comparação ao capim $(47,17 \%)$ pode ter contribuído para esse comportamento. Evangelista et al. (1999) encontraram efeito significativo da adição de $4 \%$ de polpa cítrica na silagem de capim-estrela-roxa, em todos os tempos de emurchecimento ( $0,1,2$ e 3 horas), sobre os teores de FDA, relatando que o maior aumento, decorrente da presença do aditivo, foi inferior a duas unidades percentuais. Bernardino et al. (2005) não notaram influência da adição de CA nos valores de FDA (valor médio de 53,6\%) da silagem de capimelefante com 0, 10, 20,30 e 40\% de CA e atribuíram este fato à semelhança entre os valores de FDA da casca e do capim ensilado. Em comparação aos resultados deste experimento, Crestana et al. (2001) observaram, ao incluírem 5 ou 10\% de polpa cítrica em silagem de capim-tanzânia, declínio do teor de FDA de 42,5 (0\%) para 39,7 (5\%) e 39,0\% (10\%). Apesar de não terem observado diferença significativa, Ferrari Jr. \& Lavezzo (2001) notaram tendência de decréscimo nos valores de FDA da silagem de capim-elefante com a inclusão de farelo de mandioca.

Quanto aos teores de lignina da silagem, houve apenas efeito quadrático dos níveis deCA e da interaçãoCA $\times \mathrm{PR}$ $(\mathrm{P}<0,05)$ (Figura 1). Esse efeito da $\mathrm{CA}$ pode ser atribuído ao maior teor de lignina deste subproduto $(16,86 \%)$ em comparação ao do capim $(11,32 \%)$ utilizado naprodução da silagem. Bernardino et al. (2005) observaram aumento linear dos teores de lignina da silagem de capim-elefante com a adição de CA, estimando mínimo de $8,4 \%$ e acréscimo de $0,14 \%$ no teor para cada unidade percentual de CA adicionada. 
Souza et al. (2003) também verificaram efeito linear dos níveis de CA na silagem de capim-elefante, porém com menores valores de lignina (máximo de 9,02\% com inclusão de 34,8\% de CA). Segundo Van Soest (1994), a lignina é o fator mais significante que limita a disponibilidade da parede celular da planta aos animais herbívoros nos sistemas de digestão anaeróbios, sendo considerada um dos fatores antinutricionais da CA.

A digestibilidade in vitro da MS (DIVMS) sofreu efeito quadrático da inclusão de $\mathrm{CA}$ e do $\mathrm{PR}(\mathrm{P}<0,05)$ (Figura 1). A redução na DIVMS com a inclusão de CA pode ser atribuída à menor DIVMS deste subproduto, decorrente do elevado teor de lignina.

Resultados semelhantes foram observados por Bernardino et al. (2005), que encontraram efeito linear decrescente da inclusão de CA na silagem, estimando redução de $0,24 \%$ na DIVMS para cada unidade de casca adicionada. De forma semelhante, Souza et al. (2003) verificaram redução linear de $0,14 \%$ no valor da DIVMS por unidade de CA adicionada, sendo registrados valores de 64,$48 ; 63,24 ; 62,00 ; 60,77$ e 59,63\% de digestibilidade para os níveis de $0 ; 8,7 ; 17,4 ; 26,1$ e $34,8 \%$ de CA, respectivamente, superiores aos encontrados neste experimento, provavelmente em decorrência da maior digestibilidade $(54,76 \%)$ e do menor teor de lignina $(8,69 \%)$ da casca avaliada por esses autores. Quadros et al. (2002), utilizando vacas canuladas no rúmen, verificaram que a degradabilidade efetiva foi maior na silagem de capim-elefante sem CA e diminuiu à medida que aumentou o percentual de CA. Ressalta que, mesmo com maior digestibilidade da silagem sem CA, em razão dos valores de $\mathrm{pH}$ e de $\mathrm{N}-\mathrm{NH}_{3}$, essa silagem pode ter apresentado fermentações indesejáveis e, conseqüentemente, ter resultado em forragem de menor valor nutritivo. A maior DIVMS da casca moída pode ser explicada pela redução no tamanho da partícula, que promove maior superfície de contato entre os microrganismos e o substrato (Figura 5).

\section{Conclusões}

A CA foi eficiente como aditivo absorvente de umidade nas silagens de capim-elefante com 12,7\% de MS, observando-se que, quando incluída inteira, resultou em maiores teores de MS.

Apesar de não ter melhorado as características químicobromatológicas da silagem de capim-elefante, a CA podeser utilizada inteira ou moída (em níveis de até $12 \%$, com base na matéria natural) na silagem de capim-elefante, pois melhorou as características fermentativas da silagem, reduzindo os teores de nitrogênio amoniacal e promovendo valores adequados de $\mathrm{pH}$.

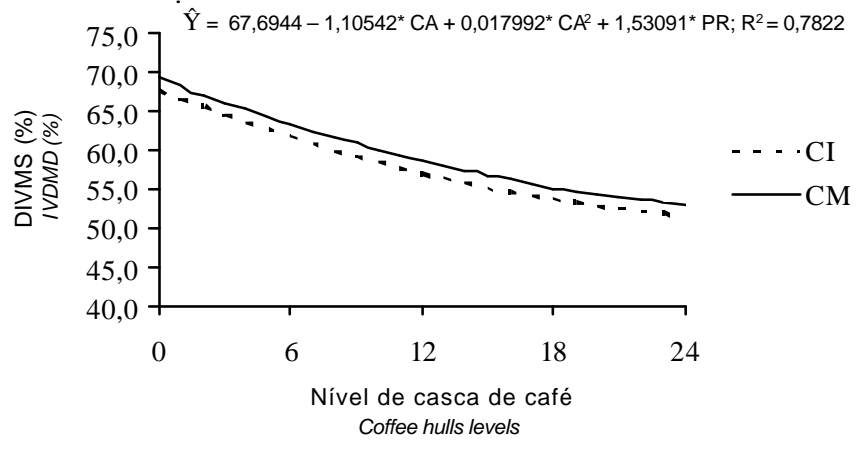

* Significativo a $5 \%$ de probabilidade pelo teste $\mathrm{t}$

* Significant at $5 \%$ probability by $t$ test

Figura 5 - Digestibilidade in vitro da MS da silagem de capimelefante produzida com diferentes níveis de casca de café inteira $(\mathrm{Cl})$ ou moída $(\mathrm{CM})$.

Figure 5 - IVDMD concentration of elephantgrass silage with different inclusion levels of coffee hulls, whole (CI) or ground (CM).

\section{Literatura Citada}

ANDRADE, J.B. Efeito da adição de rolão de milho, farelo de trigo e sacharina na ensilagem do capim-elefante (Pennisetum purpureum Schum). Botucatu: Universidade Estadual Paulista, 1995. 190p. Tese (Doutorado em Zootecnia) - Universidade Estadual Paulista, 1995.

ÁVILA, C.L.S.; PINTO, J.C.; EVANGELISTA, A.R. et al. Perfil de fermentação das silagens de capim-tanzânia com aditivos. I. Teores de matéria seca e proteína bruta. In: REUNIÃO ANUAL DA SOCIEDADE BRASILEIRA DE ZOOTECNIA, 40. 2003, Santa Maria. Anais... Santa Maria: Sociedade Brasileira de Zootecnia, 2003. (CD-ROM).

BALSALOBRE, M.A.A.; NUSSIO, L.G.; MARTHA JR., G.B. Controle de perdas na produção de silagens de gramíneas tropicais. In: REUNIÃO ANUAL DA SOCIEDADE BRASILEIRA DE ZOOTECNIA, 38., 2001, Piracicaba. Anais... Piracicaba: Fundação de Estudos Agrários Luiz de Queiroz, 2001. p.890-911.

BERNARDINO, F.S.; GARCIA, R.; ROCHA, F.C. et al. Produção e características do efluente e composição bromatológica da silagem de capim-elefante contendo diferentes níveis de casca de café. Revista Brasileira de Zootecnia, v.34, n.6, p.21852191, 2005 (supl.).

BOLSEN, K.K.; LIN, B.E.; BRENT, B.E. et al. Effect of silage additives on the microbial succession and fermentation process of alfalfa and corn silage. Journal of Dairy Science, v.75, n.11, p.3066-3083, 1992.

CABEZAS, M.T.; FLORES, A.; EGAÑA, J.I. Uso de pulpa de café en la alimentación de ruminantes. In: BRAHAM, J.E.; BRESSANI, R. (Eds.) Pulpa de café. Bogotá: Instituto de Nutrición de Centro América y Panamá, 1978. p.45-67.

CORRÊA, L.A.; CORDEIRO, J.A. Silagem de capim como estratégia de manejo intensivo de pastagens. São Carlos: Embrapa Pecuária Sudeste, 2000. 6p. (Documentos, 26).

CRESTANA, R.F.; AGUIAR, R.N.S.; BALSALOBRE, M.A.A. et al. Efeito da fermentação na fração fibra de silagens de capim Tanzânia. In: REUNIÃO ANUAL DA SOCIEDADE BRASILEIRA DE ZOOTECNIA, 38., 2001, Piracicaba. Anais... Piracicaba: Sociedade Brasileira de Zootecnia, 2001. p.354-355.

EVANGELISTA, A.R.; LIMA, J.A.; BERNARDES, T.F. Características da silagem do capim estrela roxa (Cynodon nlemfluensis L.). In: REUNIÃO ANUAL DA SOCIEDADE 
BRASILEIRA DE ZOOTECNIA, 36., 1999, Porto Alegre. Anais... Porto Alegre: Sociedade Brasileira de Zootecnia, 1999. (CD-ROM).

EVANGELISTA, A.R.; SILVA, L.V.; CORREIA, L.F. A. Efeito de três diferentes formas físicas de polpa cítrica, como aditivo seco na silagem de capim napier (Pennisetum. purpureum, Schum). In: REUNIÃO ANUAL DA SOCIEDADE BRASILEIRA DE ZOOTECNIA, 33., 1996, Fortaleza. Anais... Fortaleza: Sociedade Brasileira de Zootecnia, 1996. p.352-353.

FERRARI JR., E.; LAVEZZO, W. Qualidade da silagem de capimelefante (Pennisetum purpureum Schum.) emurchecido ou acrescido de farelo de mandioca. Revista Brasileira de Zootecnia, v.30, n.5, p.1424-1431, 2001

HERLING, V.R.; NAKASUKA, C.; KOBAYASHI, E.T. et al. Avaliação do capim-elefante (Pennisetum. purpureum, Schum cv. Napier) submetido a diferentes tratamentos e ensilado em mine-silos. In: REUNIÃO ANUAL DA SOCIEDADE BRASILEIRA DE ZOOTECNIA, 35., 1998, Botucatu. Anais... Botucatu: Sociedade Brasileira de Zootecnia, 1998. p.263-265.

IGARASI, M.S. Controle de perdas na ensilagem de capim Tanzânia (Panicum maximum Jack cv. Tanzânia) sob os efeitos do teor de matéria seca, do tamanho de partícula, da estação do ano e da presença do inoculante bacteriano. Piracicaba: Escola Superior de Agricultura "Luiz de Queiroz", 2002. 152p. Dissertação (Mestrado em Zootecnia) - Escola Superior de Agricultura "Luiz de Queiroz", 2002.

JONES, R.; JONES, D.I.H. The effect of in-silo effluent absorbents on effluent production and silage quality. Journal of Agricultural Engineering Research, v.64, p.173-186, 1996.

LAVEZZO, W. Silagem de capim-elefante. Informe Agropecuário, v.11, n.132, p.50-57, 1985.

McDONALD, P. The biochemistry of silage. New York: John Wiley \& Sons, 1981. 207p.

PINTO, J.C.; ÁVILA, C.L.S.; SANTOS, I.P.A. et al. Avaliação das características da silagem de capim-aruana adicionadas com polpa cítrica peletizada. In: REUNIÃO ANUAL DA SOCIEDADE BRASILEIRA DE ZOOTECNIA, 41., 2004, Campo Grande. Anais... Campo Grande: Sociedade Brasileira de Zootecnia, 2004. (CD-ROM).
QUADROS, D.G.; FIGUEIREDO, M.P.; CARDOSO JR., N.S. et al. Perfil dos produtos da fermentação e degradabilidade in vitro da matéria seca da silagem de capim elefante com diferentes percentuais de casca de café. In: REUNIÃO ANUAL DA SOCIEDADE BRASILEIRA DE ZOOTECNIA, 39., 2002, Recife. Anais... Recife: Sociedade Brasileira de Zootecnia, 2002. (CD-ROM).

SILVA, D.J.; QUEIROZ, A.C. Análise de alimentos: métodos químicos e biológicos. Viçosa, MG: Editora UFV, 2002. 235p.

SOUZA, A.L.; BERNARDINO, F.S.; GARCIA, R. et al. Valor nutritivo de silagem de capim-elefante (Pennisetum purpureum Schum.) com diferentes níveis de casca de café. Revista Brasileira de Zootecnia, v.32, n.4, p.828-833, 2003.

SOUZA, A.L.; BERNARDINO, F.S.; GARCIA, R. et al. Valor nutritivo de silagem de capim-elefante (Pennisetum purpureum Schum.) com diferentes níveis de casca de café. In: REUNIÃO ANUAL DA SOCIEDADE BRASILEIRA DE ZOOTECNIA, 38., 2001, Piracicaba. Anais... Piracicaba: Sociedade Brasileira de Zootecnia, 2001. (CD-ROM).

UNIVERSIDADE FEDERAL DE VIÇOSA - UFV. SAEG - Sistema de análises estatísticas e genéticas. Versão 7.1. Viçosa, MG: Fundação Arthur Bernardes, 1997. 150p. (Manual do usuário).

Van SOEST, P.J. Nutritional ecology of the ruminant. 2.ed. Ithaca: Cornell University Press, 1994. 476p.

VILELA, F.G.; OLALQUIAGA-PEREZ, J.R.; TEIXEIRA, J.C. et al. Uso da casca de café melosa em diferentes níveis na alimentação de novilhos confinados. Ciência e Agrotecnologia, v. 25, n.1, p. 198-205, 2001. 